\title{
Papers
}

\section{Randomised trial of analgesic effects of sucrose, glucose, and pacifiers in term neonates}

\author{
R Carbajal, X Chauvet, S Couderc, M Olivier-Martin
}

\begin{abstract}
Objectives To assess and compare the analgesic effects of orally administered glucose and sucrose and pacifiers. To determine the synergistic analgesic effect of sucrose and pacifiers.

Design Randomised prospective study with validated behavioural acute pain rating scale.

Setting Maternity ward.

Participants 150 term newborns undergoing venepuncture randomly assigned to one of six treatment groups: no treatment; placebo $(2 \mathrm{ml}$ sterile water); $2 \mathrm{ml} \mathrm{30 \%} \mathrm{glucose;} 2 \mathrm{ml} \mathrm{30 \%} \mathrm{sucrose;} \mathrm{a} \mathrm{pacifier;}$ and $2 \mathrm{ml} \mathrm{30 \%} \mathrm{sucrose} \mathrm{followed} \mathrm{by} \mathrm{a} \mathrm{pacifier.}$

Results Median (interquartile) pain scores during venepuncture were 7 (5-10) for no treatment; 7 (6-10) for placebo (sterile water); 5 (3-7) for $30 \%$ glucose; 5 (2-8) for 30\% sucrose; 2 (1-4) for pacifier; and 1 (1-2) for 30\% sucrose plus pacifier. Mann-Whitney U test $\mathrm{P}$ values for comparisons of $30 \%$ glucose, $30 \%$ sucrose, pacifier, and 30\% sucrose plus pacifier versus placebo (sterile water) were $0.005,0.01,<0.0001$, and $<0.0001$, respectively. Differences between group median pain scores for these comparisons were 2 (95\% confidence interval 1 to 4 ), 2 (0 to 4 ), 5 (4 to 7), and 6 (5 to 8 ), respectively. P values for comparisons of $30 \%$ glucose, $30 \%$ sucrose, and 30\% sucrose plus pacifier versus pacifier were $0.0001,0.001$, and 0.06 , respectively. Differences between group medians for these comparisons were 3 (2 to 5), 3 (1 to 5 ), and 1 (0 to 2), respectively.

Conclusion The analgesic effects of concentrated sucrose and glucose and pacifiers are clinically apparent in newborns, pacifiers being more effective than sweet solutions. The association of sucrose and pacifier showed a trend towards lower scores compared with pacifiers alone. These simple and safe interventions should be widely used for minor procedures in neonates.
\end{abstract}

\section{Introduction}

Routine medical care of newborns includes blood sampling during the first days of life. These procedures are performed even in babies who are not sick, and, of course, they are more common in ill infants who need neonatal intensive care. The ability of neonates to perceive and react to pain has recently been acknowledged. $^{12}$ Treating pain in the newborn is essential; firstly, for ethical reasons and, secondly, because pain can lead to decreased oxygenation, haemodynamic instability, or increased intracranial pressure. ${ }^{2}$ Recent research has shown that even short term pain can have lasting negative effects. ${ }^{3}$ This knowledge has led many neonatal teams to develop strategies to alleviate pain caused by diagnostic and therapeutic procedures undergone by newborns. For neonates receiving intensive care it is widely accepted that central analgesics, administered intravenously, should be used to relieve pain. Infants who are less sick or who are not in neonatal intensive care units, however, usually do not receive any analgesic for painful procedures. Obviously, central analgesics can not be used for occasional blood sampling performed in newborns who do not need intensive care; it is therefore essential to find simple, acceptable, and well tolerated methods to reduce pain in these infants.

Some recent studies have reported that simple and benign interventions-such as oral sugar solutions, milk, ${ }^{5}$ or sucking a pacifier (commonly called dummies in the United Kingdom $)^{4}$-reduce pain in neonates during procedures. The analgesic effects of sucrose have been reported in term and preterm newborn infants. ${ }^{7-11}$ Glucose and non-sucrose sweet tasting solutions have also been found to have analgesic effects. ${ }^{12-14}$

Almost all of these previous studies regarding the analgesic effects of oral sugar, milk, or pacifiers have used crying as the principal tool to assess pain. ${ }^{15}$ But, although closely related, crying is not unique to pain. Hence, use of crying alone as an indication of pain has severe limitations. ${ }^{15}{ }^{16}$ In fact evaluation of pain in newborns is difficult, and we have to rely on reactions such as changes in behaviour, modification in physiological variables, or release of stress hormones to infer pain. Assessments that rely on various behavioural changes seem more accurate for evaluation of pain in newborns.

Recently, a behavioural acute pain rating scale for neonates, DAN (Douleur Aiguë du Nouveau-né), has been validated. ${ }^{17}$ This scale scores pain from 0 to 10 , where 0 is no pain and 10 maximum pain. It evaluates three items: facial expression, limb movements, and vocal expression (table 1). In the validation study of this scale, two independent observers evaluated newborns during both painful and placebo or dummy procedures. The scale showed a good sensitivity and specificity because all possible scores were obtained; these

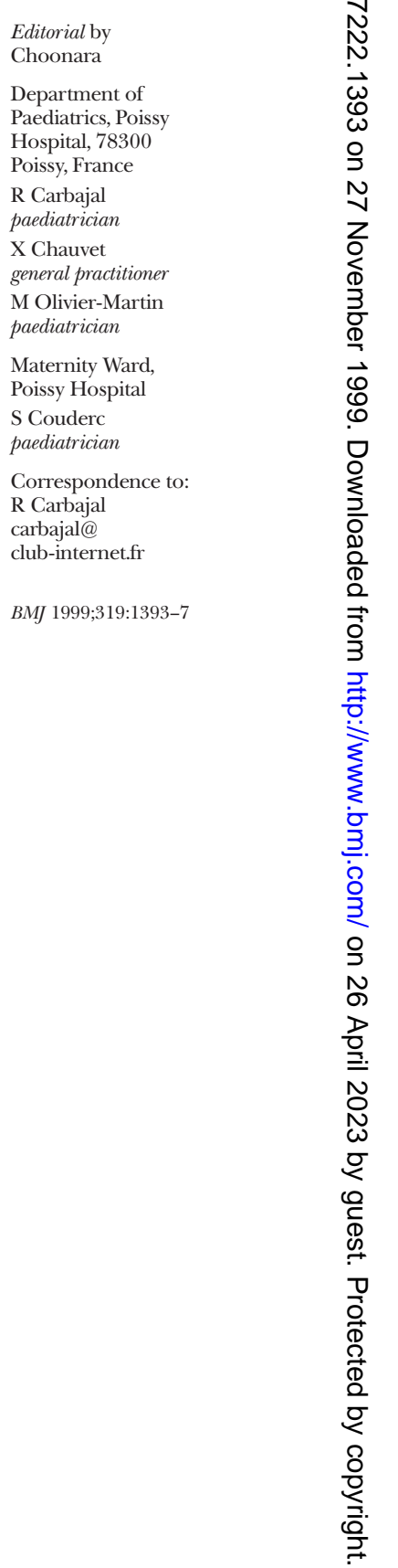




\begin{tabular}{lc} 
Table 1 DAN*: A behavioural acute pain rating scale for neonates & Score \\
\hline Measure & \\
\hline Facial expressions & 0 \\
\hline Calm & 1 \\
\hline Snivels and alternates gentle eye opening and closing & 2 \\
\hline Determine intensity of one or more of: eye squeeze, brow bulge, nasolabial furrow: & 3 \\
\hline Mild, intermittent with return to calm & 4 \\
\hline Moderate & 0 \\
\hline Very pronounced, continuous & \\
\hline Limb movements & 1 \\
\hline Calm or gentle movements & 2 \\
\hline Determine intensity of one or more of the following signs: pedals, toes spread, legs tensed \\
$\quad$ and pulled up, agitation of arms, withdrawal reaction: \\
\hline Mild, intermittent with return to calm & 3 \\
\hline Moderate & 0 \\
\hline Very pronounced, continuous & 1 \\
\hline Vocal expression & 2 \\
\hline No complaints & 3 \\
\hline Moans briefly; for intubated child, looks anxious or uneasy & \\
\hline Intermittent crying; for intubated child, gesticulations of intermittent crying & \\
\hline Long lasting crying, continuous howl; for intubated child, gesticulations of continuous crying & 3 \\
\hline${ }^{*}$ Douleur Aiguë du Nouveau-né. &
\end{tabular}

were $\geqslant 3$ in $95 \%$ of painful procedures and $\leqslant 2$ in $88 \%$ of dummy procedures. High intercorrelation of items (internal consistency) was confirmed by a Cronbach's coefficient $\alpha$ of 0.88 , and a good interrater agreement was shown by a Krippendorf's $r$ of 91.2.

The present study was undertaken to assess and compare the analgesic effects of orally administered glucose and sucrose and pacifiers with a validated behavioural acute pain rating scale and to determine the synergistic analgesic effect of sucrose and pacifiers during venepuncture in term neonates.

\section{Methods}

Protocol

This prospective, randomised clinical study was designed to include normal full term newborn infants treated in the maternity ward of the Poissy Hospital. The study protocol and the letter of permission addressed to parents were approved by the local committee for the protection of human subjects in medical research, according to current law in France. Written informed consent was obtained from a parent of each newborn before the infant participated in the study. The inclusion criteria were newborn aged $\geqslant 24$ hours who underwent venepuncture as part of routine medical care (the main reasons were screening for phenylketonuria and hypothyroidism and serum bilirubin sampling); no feeding for the previous 30 minutes; Apgar score $\geqslant 7$ at five minutes, and availability of one investigator (XC) who was present eight hours a day, at the time when most non-urgent blood samples were drawn, every day from Monday to Friday during the study period. Exclusion criteria were medical instability in the infant and naloxone administration during the previous 24 hours. All venepunctures were performed by two experienced nurses using the "broken needle" technique.

The primary outcome measure was the evaluation of pain induced by venepuncture in newborns with the DAN scale. Calculation of sample size with means and SD of 2.5 showed that to achieve $80 \%$ power and $5 \%$ significance to detect a 2 point difference in DAN scale among groups, 25 newborns were required in each one of the six groups planned. A subsequent power analysis adapted for the non-parametric MannWhitney U test showed that 25 newborns per group would give a $80 \%$ power and $1 \%$ significant level. The six groups were no treatment; placebo $(2 \mathrm{ml}$ sterile

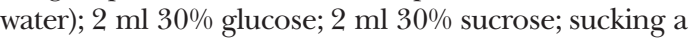

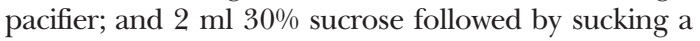
pacifier. Commercial vials of sterile water and 30\% glucose were used; sterile 30\% sucrose solutions were prepared in advance by a pharmacist.

\section{Assignment}

A hundred and fifty infants expected to be included in the study were randomly assigned to one of the six groups. Randomisation was performed in advance with a random number table by an assistant not involved in the study, and treatment allocations were inserted in opaque sealed envelopes numbered 1 to 150; investigators were blind to these allocations. Codes of allocation were kept secret by the assistant who performed randomisation, and they were broken only after the inclusion of the last neonate.

\section{Masking}

Newborn infants were taken to a quiet nursery for venepunctures. As pain evaluation with the DAN scale needed observation of leg and foot movements these were uncovered. The observer started evaluations with an assessment of the arousal state by using Prechtl's observational rating system ${ }^{18}$ : (1) eyes closed, regular respiration, no movements; (2) eyes closed, irregular respiration, gross movements; (3) eyes open, no gross movements; (4) eyes open, continual gross movements, no crying; (5) eyes open or closed, fussing, or crying. The observer then left the room and the infant was prepared for the procedure. A research assistant opened a consecutively numbered envelope that contained the treatment assigned for each infant. Two minutes before venepuncture the allocated solution was administered for 30 seconds by a sterile syringe into the infant's mouth. A pacifier (standard nipple stuffed with a gauze square for resistance) was also given two minutes before venepuncture and held gently in the infant's mouth by an assistant throughout the procedure. Pain was assessed during venepuncture and blood collection by the observer (XC). As pain evaluation was based on a behavioural scale blinding to the pacifier was not possible.

Statistical analysis was performed with SIMSTAT 3.5 software. Median scores of all groups were compared with the non-parametric Mann-Whitney $U$ test. Because multiple pairwise comparisons were made $\mathrm{P}=0.01$ was considered significant.

\section{Results}

From April to the end of June 1997 we studied 150 newborn infants in six equal sized groups. All parents asked gave their consent for their infants to participate in the study. There were no withdrawals. Fifty neonates who underwent venepuncture and were potentially eligible were not included in the study because XC was not available; their perinatal characteristics were similar to those included in the study. Figure 1 shows a trial profile with participant flow. Birth weight, gestational age, Apgar scores, postnatal age, sex distri- 


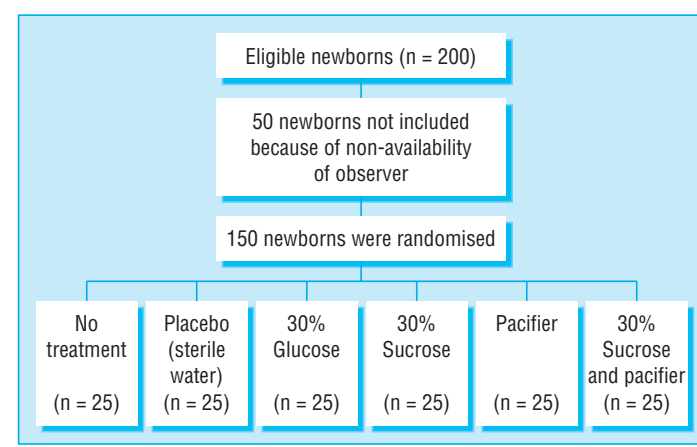

Fig 1 Trial profile and participant flow; all randomised newborns completed trial

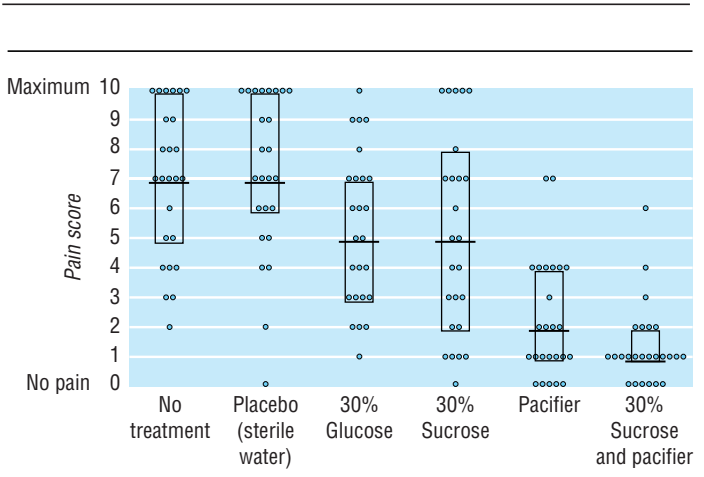

Fig 2 Pain evaluation with DAN scale (0 to 10) during venepuncture in 150 newborns randomised to six equal sized groups, with values for individual infants, median values, and interquartile ranges (for $30 \%$ sucrose and pacifier lower quartile coincides with median value)

bution, type of delivery, and arousal state for each group are shown in table 2 . There were no substantial differences among the groups concerning these perinatal characteristics. Individual pain scores, median values, and interquartile ranges for each group during venepunctures are presented in figure 2 . The median (interquartile) pain scores during venepuncture were 7 (5-10) for no treatment, 7 (6-10) for placebo sterile water, 5 (3-7) for $30 \%$ glucose, 5 (2-8) for $30 \%$ sucrose, 2 (1-4) for pacifier, and 1 (1-2) for $30 \%$ sucrose plus pacifier. Comparisons of median pain scores among groups are shown in table 3 . No adverse effects were noted in any infant.

\section{Discussion}

This study has three main results. Firstly, during venepuncture in newborns the analgesic effects of $30 \%$ glucose, 30\% sucrose, and non-nutritive sucking of pacifiers are large enough to be clinically significant and can thus be detected by a behavioural rating scale for acute pain. Secondly, 30\% glucose, which is readily available in any hospital, showed at least the same analgesic effect as $30 \%$ sucrose, which is usually more difficult to obtain. Thirdly, the non-nutritive sucking of a pacifier was more effective than the oral administration of $30 \%$ glucose or $30 \%$ sucrose. It should be noted that although comparison of $30 \%$ sucrose versus placebo showed a $\mathrm{P}$ value of 0.01 and a median difference of 2 points, the $95 \%$ confidence interval of the latter included 0 . We believe that this discrepancy was mainly due to the fact that the sample included was rather small; this sample had been calculated by using parametric measures-means and SD-whereas the analysis was performed with a non-parametric test. Although the administration of $2 \mathrm{ml} \mathrm{30 \%} \mathrm{glucose} \mathrm{and}$ $30 \%$ sucrose reduced pain in neonates, the median pain score in each of these groups was 5.0, which is still relatively high. Therefore, we consider that although sweet solutions are effective in reducing pain in newborns they are not perfect analgesics.

We found that non-nutritive sucking provided a better analgesic effect than sweet solutions. Other authors have reported on the pacifying and comforting effects of non-nutritive sucking, ${ }^{19}{ }^{20}$ but to our knowledge no comparison between pacifiers and sweet

Table 2 Perinatal characteristics of 150 newborns included in study of analgesic effects of sucrose, glucose, and pacifiers. Numbers are nedian (range) unless stated otherwise

\begin{tabular}{|c|c|c|c|c|c|c|}
\hline Detail & $\begin{array}{l}\text { No treatment } \\
(\mathrm{n}=25)\end{array}$ & $\begin{array}{l}\text { Placebo-sterile } \\
\text { water }(n=25)\end{array}$ & $\begin{array}{c}30 \% \text { Glucose } \\
(n=25)\end{array}$ & $\begin{array}{l}30 \% \text { Sucrose } \\
(\mathrm{n}=25)\end{array}$ & Pacifier $(n=25)$ & $\begin{array}{c}30 \% \text { Sucrose } \\
\text { plus pacifier } \\
(n=25)\end{array}$ \\
\hline Gestational age (weeks) & $39(37-41)$ & $40(37-41)$ & $40(37-41)$ & $40(37-42)$ & $40(37-41)$ & $39(37-41)$ \\
\hline Birth weight $(\mathrm{g})$ & $3320(2320-4080)$ & $3280(2460-4050)$ & $3340(2400-3950)$ & $3420(2260-4125)$ & $3370(2460-4000)$ & $3320(2630-3950)$ \\
\hline No of boys/girls & $16 / 9$ & $16 / 9$ & $14 / 11$ & $11 / 14$ & $16 / 9$ & $15 / 10$ \\
\hline No of vaginal/caesarean deliveries & $22 / 3$ & $22 / 3$ & $21 / 4$ & $22 / 3$ & $23 / 2$ & $24 / 1$ \\
\hline Apgar score (5 min) & $10(7-10)$ & $10(7-10)$ & $10(9-10)$ & $10(9-10)$ & $10(10-10)$ & $10(8-10)$ \\
\hline $\begin{array}{l}\text { Postnatal age (interquartile range) } \\
\text { (days) }\end{array}$ & $3(3-4)$ & $4(3-4)$ & $4(3-4)$ & $4(3-5)$ & $4(3-4)$ & $3(2-4)$ \\
\hline Arousal state score & $3(1-5)$ & $3(1-5)$ & $3(1-5)$ & $3(1-5)$ & $3(1-5)$ & $3(1-3)$ \\
\hline
\end{tabular}

Table 3 Comparisons of median pain scores among groups

\begin{tabular}{|c|c|c|c|c|}
\hline Detail & $30 \%$ glucose (MPS=5) & $30 \%$ sucrose (MPS=5) & Pacifier (MPS=2) & $\begin{array}{l}30 \% \text { sucrose + pacifier } \\
\text { (MPS=1) }\end{array}$ \\
\hline \multicolumn{5}{|l|}{ Placebo (MPS=7): } \\
\hline$P$ value $^{*}$ & 0.005 & 0.01 & $<0.0001$ & $<0.0001$ \\
\hline Median difference $(95 \% \mathrm{Cl})$ & 2 (1 to 4$)$ & $2(0$ to 4$)$ & 5 (4 to 7$)$ & 6 (5 to 8$)$ \\
\hline \multicolumn{5}{|l|}{ Pacifier (MPS=2): } \\
\hline$P$ value $^{*}$ & 0.0001 & 0.001 & NA & 0,06 \\
\hline Median difference $(95 \% \mathrm{Cl})$ & $3(2$ to 5$)$ & $3(1$ to 5$)$ & NA & 1 (0 to 2$)$ \\
\hline
\end{tabular}

MPS: median pain score. NA: not applicable.

${ }^{\star}$ For Mann-Whitney U test. 
solutions had been done previously. It has also been reported that oral sucrose via a nipple is effective for pain relief in neonatal circumcision. ${ }^{11}$ We consider, however, that this analgesic effect may be essentially due to the pacifier more than to sucrose itself.

Regarding the synergistic effect of sucrose and pacifiers, this was clearly established in the comparison with placebo as median scores in placebo, sucrose, and sucrose plus pacifier groups were 7, 5, and 1, respectively. A trend towards lower scores was observed in the group given 30\% sucrose plus pacifier (median score 1) compared with the group given a pacifier alone (median score 2). This difference did not reach significance $(\mathrm{P}=0.06)$. It should be mentioned, however, that the study was designed to detect a 2 point difference between the groups and therefore it lacked enough power to detect a 1 point difference. It has also been suggested that the administration of sterile water may have some analgesic effect. ${ }^{21}$ We did not find any difference between the group given sterile water and the one given no intervention. One possible explanation is that the authors of that study used only measures of crying and not a behavioural pain scale. ${ }^{21}$

The rapid onset of the analgesic effect strongly suggests a mechanism activated by the presence of the solution in the mouth rather than any effect after ingestion. The pain relief elicited by sweet solutions is probably mediated by the activation of endogenous opioids; this view is supported by the fact that the effect can be blocked by the administration of an opioid antagonist. ${ }^{22}$

The precise mechanism by which pacifiers relieve pain remains to be identified. It has been suggested that two processes may play a part. ${ }^{19}$ The first is sensory dominance; as sucking is a powerful source of perceptual information for infants the sensations it elicits may have priority in deployment of attentional resources and thus effectively mute pain. The second hypothesis is that pacifiers reduce infant response to pain by facilitating self regulation. Provision of pacifiers enhances infants' ability to regulate their response to pain by giving the opportunity for sucking. Elicitation of sucking with a pacifier enables infants to control one source of incoming stimuli-oral stimulation-through their own activity. Pacifiers are accepted by most newborns, if not all, because they associate non-nutritive sucking with a pleasurable activity.

\section{Limitations}

Interpretation of the results of this study should acknowledge two limitations. Firstly, although the observer was blind to the type of solution administered he was not blind to the administration of a pacifier to newborns; it was impossible to avoid this potential bias because the study was based on a behavioural pain scale. The objectivity of the observer, however, can be underlined by the fact that the median pain scores of the two groups pacifier alone and pacifier plus sucrose tended to be different. Secondly, although the validation study of the DAN scale has shown that it discriminates pain in newborns, no study has proved yet that this scale can grade the degree of perception of pain. We assumed that the more pronounced the facial expressions, the limb movements, and the vocal expressions the greater the pain in the newborn.
- The analgesic effects on newborn infants of sucrose, glucose, and pacifiers can be clearly detected by a behavioural pain rating scale

- Pacifiers had a better analgesic effect than sweet solutions

- A synergistic effect was found with a combination of sucrose and pacifiers

- Sweet solutions and pacifiers constitute simple and safe interventions that can be used to provide analgesia in newborns during minor procedures

\section{Minor procedures}

Minor procedures are common in newborns, and effective analgesia is seldom used in this setting. The non-nutritive sucking of a pacifier, the oral administration of concentrated glucose or sucrose, or, even better, the association of an oral sweet solution with the nonnutritive sucking of pacifier constitute simple, noninvasive, and benign manoeuvres that can relieve pain in newborns during minor procedures such as venepuncture, heel lancing, spinal tap, intramuscular vitamin $\mathrm{K}$ injection, or subcutaneous erythropoietin injection, and therefore we think that they should be routinely used. We insist on "minor procedures" as we consider that these simple interventions are not suitable for more aggressive procedures, when stronger analgesics, including central ones, should be administered.

We thank the nursing staff of the maternity ward of the Poissy Hospital for their help during the study and Dr Nicolas Simon, chief of the emergency department, Poissy Hospital, for reading the paper.

Contributors: RC conceived and designed the study, supervised data collection, performed the statistical analysis, analysed the results, and wrote the final manuscript. XC performed data collection, analysed the results, and participated in writing the manuscript. SC participated in the design of the study and in writing the manuscript. MOM participated in the design of the study, analysed the results, and participated in writing the manuscript.

Funding: No external funding.

Competing interests: None declared.

1 Anand KJS, Carr DB. The neuroanatomy, neurophysiology and neurochemistry of pain, stress, and analgesia in newborns and children. Ped Clin NAm 1989;36:795-822.

2 Anand KJS, Hickey PR. Pain and its effects in the human neonate and fetus. N Engl J Med 1987;317:1321-9.

3 Taddio A, Goldbach M, Ipp M, Stevens B, Koren G. Effect of neonatal circumcision on pain responses during vaccination in boys. Lancet 1995;345:291-2.

4 Blass EM, Hoffmeyer LB. Sucrose as an analgesic for newborns infants. Pediatrics 1991;87:215-8.

5 Blass EM. Milk-induced hypoalgesia in human newborns. Pediatrics 1997;99:825-9.

6 Gunnar M, Fisch RO, Malone S. The effects of pacifying stimulus on behavioral and adrenocortical responses to circumcision.JAm Acad Child Adolescs Psychiatry 1984;23:34-8.

7 Ramenghi LA, Wood CM, Griffith GC, Levene MI. Reduction of pain response in premature infants using intraoral sucrose. Arch Dis Child 1996;74:F126-8.

8 Rushforth JA, Levene MI. Effect of sucrose on crying in response to heel stab. Arch Dis Child 1993;69:388-9.

9 Haouari N, Wood C, Griffiths G, Levene M. The analgesic effect of sucrose in full term infants: a randomised controlled trial. BMJ 1995;310: 1498-500.

10 Bucher H, Moser T, Siebenthal KV, Keel M, Wolf M, Duc G. Sucrose reduces pain reaction to heel lancing in preterm infants: a placebocontrolled, randomized and masked study. Pediatr Res 1995;38:332-5.

11 Herschel M, Khoshnood B, Ellman C, Maydew N, Mittendorf R. Neonatal circumcision. Arch Pediatr Adolesc Med 1998;152:279-84. 
12 Blass EM, Smith BA. Differential effects of sucrose, fructose, glucose, and lactose on crying in 1- to 3-day-old human infants: qualitative and quantitative considerations. Dev Psychol 1992;28:804-10.

13 Ramenghi LA, Griffith GC, Wood CM, Levene MI. Effect of non-sucrose sweet tasting solution on neonatal heel prick responses. Arch Dis Child 1996;74:F129-31.

14 Skogsdal Y, Eriksson M, Schollin J. Analgesia in newborns given oral glucose. Acta Paediatr 1997;86:217-20.

15 Stevens B, Taddio A, Ohlsson A, Einarson T. The efficacy of sucrose for relieving procedural pain in neonates-a systematic review and meta-analysis. Acta Paediatr 1997;86:837-42.

16 Editorial. Pacifiers, passive behaviour, and pain. Lancet 1992;339:275-6.

17 Carbajal R, Paupe A, Hoenn E, Lenclen R, Olivier-Martin M. DAN: une échelle comportementale d'évaluation de la douleur aiguë du nouveau-né. Arch Pédiatr 1997;4:623-8.
18 Prechtl HFR, Beintema DJ. The neurological examination of the full term newborn infant. Clinics in developmental medicine. No 12. London: Heinemann, 1964.

19 Campos RG. Rocking and pacifiers: two comforting interventions for heelstick pain. Res Nursing Health 1994;17:321-31.

20 Field T, Goldson E. Pacifying effects, of non-nutritive sucking on term and preterm neonates during heelstick procedures. Pediatrics 1984;74:1002-5.

21 Allen KD, White DD, Walburn JN. Sucrose as an analgesic agent for infants during immunization injections. Arch Pediatr Adolesc Med 1996:150:270-4.

22 Blass EM, Fitzgerald E. Milk induced analgesia and comforting in 10-dayold rats: opioid mediation. Pharmacol Biochem Behav 1988;29:9-13.

(Accepted 23 August 1999)

\title{
Rates and implications of caesarean sections in Latin America: ecological study
}

\author{
José M Belizán, Fernando Althabe, Fernando C Barros, Sophie Alexander
}

\begin{abstract}
Objectives To estimate the incidences of caesarean sections in Latin American countries and correlate these with socioeconomic, demographic, and healthcare variables.

Design Descriptive and ecological study. Setting 19 Latin American countries. Main outcome measures National estimates of caesarean section rates in each country.

Results Seven countries had caesarean section rates below $15 \%$. The remaining 12 countries had rates above $15 \%$ (range $16.8 \%$ to $40.0 \%$ ). These 12 countries account for $81 \%$ of the deliveries in the region. A positive and significant correlation was observed between the gross national product per capita and rate of caesarean section $\left(r_{s}=0.746\right)$, and higher rates were observed in private hospitals than in public ones. Taking $15 \%$ as a medically justified accepted rate, over 850000 unnecessary caesarean sections are performed each year in the region. Conclusions The reported figures represent an unnecessary increased risk for young women and their babies. From the economic perspective, this is a burden to health systems that work with limited budgets.
\end{abstract}

\section{Introduction}

Caesarean sections increase the health risks for mothers and babies as well as the costs of health care compared with normal deliveries. ${ }^{1-5}$ Concern has been expressed at the growing rates of caesarean section in some countries of Latin America over the past few years. ${ }^{6}{ }^{7}$ Some developed countries have apparently controlled the increase in caesarean section, although the rates may still be high. ${ }^{8-10}$ However, in other developed countries, caesarean section rates are still increasing and are a matter of concern. ${ }^{11}{ }^{12}$

Information on rates of caesarean section is not easily obtained for most Latin American countries because of a lack of good national records. We estimated the recent incidence of caesarean section in several Latin American countries using different sources of information and correlated these rates with the socioeconomic, demographic, and health variables.

\section{Methods}

We studied the Spanish, Portuguese, and French speaking American developing countries. Belize, Surinam, Guyana, and the English and Dutch speaking Caribbean countries were not included. Assistance with deliveries in all Latin American countries is provided by at least two types of hospital: public and private. Public hospitals are free of charge for anyone whereas private hospitals charge patients for their assistance directly or indirectly through private health insurance. Some countries (such as Guatemala, Colombia, and Mexico) also have social security hospitals, which are free of charge but open only to people with jobs affiliated to the social security system and their families.

\section{Sources of data}

We contacted various institutions in the countries, such as ministries of health, statistical departments, scientific organisations, social security systems, and hospitals, through representatives of the Pan American Health Organisation. We requested figures for caesarean section at national, regional, or institutional levels. The information obtained came from reports of government health offices derived from routine statistical surveillance or national surveys (Argentina, Bolivia, Brazil, Ecuador, Venezuela, Mexico, Uruguay, Paraguay, El Salvador, Guatemala), the social security system (Costa Rica, Argentina, El Salvador), committees for promotion of maternal health (Mexico), private hospitals (Paraguay), and private health insurance companies (Argentina).

Data from the Demographic and Health Surveys Program were retrieved for surveys made in Latin American countries since $1990 .^{13}$ The demographic and health surveys collect information on fertility and family planning, maternal and child health, child survival, AIDS and sexually transmitted infections, and other reproductive health topics. Surveys are implemented by institutions in the host country, usually government statistical offices, and 4000 to 8000 women of childbearing age are interviewed in a standard survey. Data from the last surveys made in Bolivia, Colombia, Haiti, Peru, and Dominican Republic were used.

We also used data from the Latin American caesarean section study (Latin American Centre for
Latin American Centre for

Perinatology, Pan

American Health

Organisation, World

Health

Organisation,

Hospital de Clínicas

$\mathrm{s} / \mathrm{n}, 11000$

Montevideo,

Uruguay

José M Belizán

director

Fernando Althabe

researcher in

perinatology

Fernando C Barros

Pan American Health

Organisation

consultant

Ecole de Santé

Publique, Universite

Libre de Bruxelles,

Campues Erasme

CP 595 808,

Brussels, Belgium

Sophie Alexander

lecturer

Correspondence to:

J M Belizán

belizanj@clap.

ops-oms.org

BMJ 1999;319:1397-402

website

extra

Further details of sources of data for each country are

available on the

$B M J$ 's website

www.bmj.com 